DE ECONOMIST 158, NO. 4, 2010

\title{
LIMITS TO GROWTH IN ORGANIC SALES
}

\author{
BY \\ FRANK H. J. BUNTE*, MICHIEL A. VAN GALEN*, W. ERNO KUIPER** AND \\ GEMMA TACKEN***
}

\begin{abstract}
Summary
The price gap between organic and conventional food might explain the low market share of organics in the Netherlands. A real-life experiment was carried out in 2006 in order to determine the price sensitivity of consumer demand for organics. Consumer prices of selected organic products were reduced by up to $40 \%$ below current market levels. The price elasticity of demand was low, because not all consumers perceived the price reductions. Moreover, the offer of organic varieties is limited, as is the consumer's willingness to pay for the social attributes of organics.
\end{abstract}

Key words: field experiment, consumption, price elasticity of demand, organic food

JEL Code(s) C93, D12, Q18

\section{INTRODUCTION}

The sustainability of Dutch agriculture has been one of the key policy issues for the Dutch government in recent decades. Dutch agriculture poses major environmental problems; for example, the sector emits nitrogen, phosphorus, ammonia, biocides and greenhouse gases, it uses such scarce resources as fossil fuels and ground water, it impacts land quality, nature and biodiversity, and it causes concern about animal welfare (LEI 2009). However, agribusiness remains a major contributor to the Dutch economy. The Netherlands is the world's second largest exporter of agricultural commodities and food. Agribusiness - which includes supplying and processing industries, and the food wholesale and retail sectors - represented 9.6\% of Dutch GDP in 2007 (ibid.). It is therefore important to reconcile environmental well-being with economic interests.

In order to promote the sustainability of Dutch agriculture, the government promotes organic production (MLNV 2000, 2004). Organic farmers do

\footnotetext{
*Corresponding author: Frank H.J. Bunte, LEI, part of Wageningen UR, Alexanderveld 5, 2585 DB Den Haag, The Netherlands, e-mail: frank.bunte@wur.nl ** SSG, Wageningen University, Hollandseweg 1, $6706 \mathrm{KN}$, Wageningen, The Netherlands *** LEI, Part of Wageninen UR, Hollandseweg 1, 6706 KN, Wageningen, The Netherlands
} 
not use biocides or chemical fertilizers, they do not cut the horns, tails or bills of animals, and they provide animals with more space to move around in. This has implications for the quality of agricultural land, biodiversity and animal welfare. Organic production also sets an example for sustainability in agriculture. This is why the promotion of organic production has been a spearhead of the Dutch government for the last two decades. In the 1990s, the government focused on addressing bottlenecks in organic production. However, in the 2000s policymakers started to realize that the consumption of organics in the Netherlands is low. Long-term growth in organic production will only be possible if consumption of organics increases too.

The consumption of organic food in the Netherlands is low compared with, for instance, Denmark and Germany (Biologica 2009). One of the possible explanations for the low market share of organics in total food consumption is the substantial price gap between organic and conventional food (Van der Eerden et al. 2003). Van der Eerden et al. (ibid.) even suggest that were the price gap between organic and conventional food reduced below a certain threshold, consumers would switch en masse to organic food and conventional food might be crowded out. Until now, however, there has been little empirical evidence regarding the sensitivity of Dutch consumers' demand for organic products with respect to prices. This paper provides such evidence.

In order to determine the sensitivity of consumer demand for organics with respect to prices, this paper estimates the price elasticity of consumer demand on the basis of scanner data collected from Dutch supermarkets. In principle, one can determine the price elasticity of demand on the basis of available scanner data, provided prices and sales exhibit sufficient variation. Such research provides insight into the sensitivity of consumer prices with respect to current price levels. Examples of this type of research are Wier and Smed (2000) and Hansen $(2003$, 2004) for Denmark, and Dhar and Foltz (2003) and Glaser and Thompson $(1998,2000)$ for the USA. The price elasticity of demand for organics is elastic and can be high for specific products, such as 1\% fat milk (Glaser and Thompson 2000).

This paper differs from the literature in one key respect: the Dutch supermarkets from which the data were collected took part in a real-life experiment in which consumer prices were reduced by up to $40 \%$. The prices of selected organic products in ten local communities were reduced below their regular level for a three-month period. The experiment allowed us to study consumer behaviour at prices below current market prices. It also allowed us to investigate whether consumer buying behaviour at substantially reduced price levels does indeed differ from current buying behaviour. If the price gap between organic and non-organic food were sufficiently small, the demand for organic food might gain substantial market share and possibly crowd out non-organic food. This unique price experiment allowed us to study observations in a market environment outside the realm that is currently observable in the market. 
The paper is structured as follows. Section 2 presents an outline of the policy context. In Section 3, we describe and justify the set-up of the experiment. In Section 4, we discuss the data we used as well as the results. We present an evaluation of the results in Section 5 and our conclusion in Section 6.

\section{CONTEXT}

For the last ten years, the Dutch government has played an active role in promoting the production and consumption of organics in the Netherlands (MLNV 2000, 2004). Organic farming meets most societal requirements with respect to the environment, animal welfare and biodiversity, and by doing so sets an example with respect to sustainability for other agricultural sectors. In order to enhance the sustainability of Dutch agriculture, the government formulated an ambitious goal for organic production in the Netherlands, namely that $10 \%$ of all agricultural land should be organic by 2010 . The current figure is only $2.7 \%$ (Biologica 2010).

The government came to the conclusion at the beginning of the 2000s that organic production will only grow rapidly if the demand for organics also grows rapidly. The government therefore defined a target for the consumption of organics in the Netherlands: $5 \%$ of food consumption in euro terms in 2007. The consumption of organics did grow rapidly in the $2000 \mathrm{~s}$, but is still low. In 2009, Dutch consumers spent 647 million euros on organics, representing just $2.3 \%$ of total food expenses, which is well below the target level of 5\% (Biologica 2010). The market share of organics is higher in, for example, Austria (6\%), Denmark (5.1\%), Switzerland (4.6\%) and Germany (3.4\%). In the Netherlands, the market share of organics varies from $1.4 \%$ for groceries and $2.2 \%$ for butter and cheese, to $4.0 \%$ for fresh produce, $4.9 \%$ for other dairy products (milk and desserts) and $7.6 \%$ for eggs. Consumers buy organics primarily in organic specialty stores (39\%) and supermarkets chains (44\%).

In the mid 2000s, the government identified a major potential bottleneck for the growth in organic consumption, namely the price gap between organic and conventional food (MLNV 2004: 16). This price gap is a result of, for example, the small scale of the organic supply chain and the fact that the negative externalities in traditional farming are only partially translated into farm and consumer prices (see Bunte 2004). If a reduction in the price gap indeed leads to growth in the demand for organics, policies aimed at reducing the price gap might be pursued (MLNV 2004). Such policies might include, for example, tax deductions for sustainable production methods, ${ }^{1}$ a lower VAT rate for organics, and consumer subsidies for sustainable products comparable with those for green electricity and unleaded petrol. The consumer subsidies

1 To be specific: VAMIL, EIA, MIA, Groenfinanciering and Duurzame ondernemersaftrek. 
might be used to create sufficient scale in production and distribution to overcome the inefficiencies in production and distribution.

However, the possibility to pursue these policies might be quite limited (op. cit.: 16). A lower VAT rate for organics depends on decision making at the EU level, and as yet there is no support in the European Council for allowing a lower VAT rate for organics. Some of the tax deductions under consideration conflict with EU legislation. ${ }^{2}$ A levy or tax on conventional food would lead to several legal and economic objections, for example with respect to distorting competition between organic and conventional food. Some of the measures might have a negative impact on the administrative burden of both companies and the government. This is likely to reduce the willingness of businesses to implement the measures. Moreover, these policies might be ineffective. For example, the relation between tax deductions for farmers and consumer prices might be weak, as price transmission between farm gate and consumer prices is often imperfect.

Notwithstanding these issues, the government commissioned a real-life price experiment for organic consumption in order to find out whether a reduction in the price gap between organic and non-organic products would lead to demand growth for organic products. The government wanted to establish the sensitivity of consumer demand with respect to prices. Because the government realized that current market prices reflect the price gap, it decided to commission a real-life experiment in which the prices of organics would be subsidized in order to find out what consumers would buy at prices that are lower than those currently observed in the market. The experiment was meant to create observations for a range of market prices that are not otherwise observable.

\section{EXPERIMENT}

The experiment was set up in cooperation with the main stakeholders, that is, retailers, the marketing bureau that provided the data (IRI) and the ten communities involved. Decisions regarding the implementation of the experiment were taken in joint consultation. Stakeholder interests played a role in the decisions. The experiment lasted only 3 months because of budgetary and organizational reasons: the government did not want the experiment to become too expensive, and although retailers were very willing to cooperate, they of course wanted to limit the time and effort they would have to put into the experiment.

The set-up of the experiment involved choices related to the communities and to the products to be selected, and to a protocol for the implementation of the experiment.

\section{Duurzame ondernemersaftrek.}




\subsection{Selection of the Communities}

Ten communities were selected on the basis of the following criteria (Table 1).

1. Socio-economic characteristics. The ten communities represented both low- and medium-income communities. The sample was intended to represent average Dutch communities; high-income communities were therefore excluded. ${ }^{3}$ Prices may be expected to be an argument primarily for low- and medium-income households. The communities are also representative in terms of household composition (number of households with children) and age (number of elderly persons). Extreme deviations were excluded. There was one exception: Houten was included in the sample, although and because it is a young community. In Houten, the number of households with children deviates more than one standard deviation from the Dutch average.

2. Size. The experiment was carried out in small- and medium-sized communities. Large communities were excluded in order to keep the organization relatively simple, to exclude organic specialty stores (see criterion 4) and because the experiment might become too expensive. Very small communities were excluded in order to guarantee the presence of several retailers and of relatively large outlets with large organic product assortments.

3. Retailers located in the communities. The experiment was not to discriminate between food retailers and to include all major retail chains, particularly those with a large assortment of organic products. In some communities, discounters were active: Aldi (Zaltbommel, Coevorden, Uden, Uithuizen) and Lidl ('s Heerenberg, Coevorden, Uden, Maassluis). The discounters did not want to participate in the experiment.

4. Presence of organic specialty stores. Because the analysis would be based on retail scanner data, communities with organic specialty stores were excluded. There was one exception: there is one organic specialty store in Houten. However, this shop is not considered in the analysis.

5. Data availability. In order to simplify the data collection process, we selected only communities with retail outlets that are part of the IRI panel.

The ten communities (Table 1) represent both urban and rural as well as culturally different areas of the country, namely the south (Brabant and Limburg), the west (Holland), the centre (Utrecht and Gelderland) and the north (Overijssel, Drente, Friesland and Groningen). The table also indicates which retailers were present in the ten communities. Albert Heijn, Konmar, Super de Boer, Jumbo and Plus have a relatively large organic food assortment. Albert Heijn and Super de Boer are present in all ten communities. 
TABLE 1 - THE TEN COMMUNITIES SELECTED FOR THE EXPERIMENT

\begin{tabular}{|c|c|c|c|c|c|c|}
\hline Community & $\begin{array}{l}\text { Inhabitants } \\
\text { (2006) }\end{array}$ & $\begin{array}{l}\text { Households } \\
\text { with children } \\
\% \text { (2005) }\end{array}$ & $\begin{array}{l}\text { Aged } \\
\text { persons } \\
(65+, \%) \\
(2005)\end{array}$ & Region & $\begin{array}{l}\text { Income } \\
\text { per earner } \\
(2004)\end{array}$ & $\begin{array}{l}\text { Retailers } \\
\text { present }\end{array}$ \\
\hline 's Heerenberg & 8,150 & 40 & 16.0 & Centre & 15,400 & $\begin{array}{l}\text { AH, Coop, } \\
\text { Edah, } \\
\text { Super de } \\
\text { Boer }\end{array}$ \\
\hline Houten & 44,499 & 49 & 8.7 & Centre & 19,900 & $\begin{array}{l}\text { AH, C1000, } \\
\text { PLUS, } \\
\text { Super de } \\
\text { Boer, } \\
\text { Groene } \\
\text { Winkel }^{\mathrm{a}}\end{array}$ \\
\hline Huissen & 14,820 & 44 & 12.6 & Centre & 17,300 & $\begin{array}{l}\text { AH, Coop } \\
\text { CA, Super } \\
\text { de Boer }\end{array}$ \\
\hline Zaltbommel & 26,191 & 46 & 12.7 & Centre & 18,100 & $\begin{array}{l}\text { AH, Konmar, } \\
\text { Super de } \\
\text { Boer }\end{array}$ \\
\hline Coevorden & 36,135 & 38 & 17.0 & North & 16,000 & $\begin{array}{l}\text { AH, Coop } \\
\text { CA, Super } \\
\text { de Boer }\end{array}$ \\
\hline Uithuizen & 5,310 & 38 & 15.5 & North & 14,800 & $\begin{array}{l}\text { AH, Jumbo, } \\
\text { Super de } \\
\text { Boer }\end{array}$ \\
\hline Berkel-Enschot & 10,720 & 44 & 15.0 & South & 19,800 & $\begin{array}{l}\text { AH, PLUS, } \\
\text { Super de } \\
\text { Boer }\end{array}$ \\
\hline Uden & 40,201 & 40 & 13.4 & South & 18,100 & $\begin{array}{l}\text { AH, Edah, } \\
\text { Jan } \\
\text { Linders, } \\
\text { Jumbo, } \\
\text { PLUS, } \\
\text { Super de } \\
\text { Boer }\end{array}$ \\
\hline Brielle & 15,990 & 38 & 14.2 & West & 19,500 & $\begin{array}{l}\text { AH, Jumbo, } \\
\text { PLUS, } \\
\text { Super de } \\
\text { Boer, } \\
\text { Zomer- } \\
\text { markt }^{\mathrm{a}}\end{array}$ \\
\hline
\end{tabular}


TABLE 1 - continued

\begin{tabular}{lllllll}
\hline Community & $\begin{array}{l}\text { Inhabitants } \\
(2006)\end{array}$ & $\begin{array}{l}\text { Households } \\
\text { with children } \\
\%(2005)\end{array}$ & $\begin{array}{l}\text { Aged } \\
\text { persons } \\
(65+, \%) \\
(2005)\end{array}$ & Region & $\begin{array}{l}\text { Income } \\
\text { per earner } \\
(2004)\end{array}$ & $\begin{array}{l}\text { Retailers } \\
\text { present }\end{array}$ \\
\hline Maassluis & 31,956 & 38 & 14.4 & West & 17,800 & $\begin{array}{l}\text { AH, C1000, } \\
\text { Hoogvliet, } \\
\text { Konmar, } \\
\text { Super de } \\
\text { Boer }\end{array}$ \\
Netherlands & & & & & \\
\hline
\end{tabular}

a Specialty outlet not included in the analysis.

Source CBS: StatLine.

Albert Heijn and Super de Boer were part of the two main food retail conglomerates that were active in the Netherlands in 2006: Ahold (Albert Heijn, C1000) and Laurus (Super de Boer, Konmar, Edah). ${ }^{4}$

\subsection{Product Selection}

Products were selected on the following grounds:

1. The availability of organic varieties. Organic varieties of all the selected products were available in the major retail chains involved in the experiment. Organic varieties are identified by EKO labels. In the Netherlands, the EKO label is assigned by SKAL if the producer meets the conditions laid down in EC regulations 834/2007 and 889/2008. IRI performs checks in selected large retail outlets of several retail formula in order to find out which stock keeping units (SKUs) have an EKO label. During the experiment, IRI's list of organic SKUs was combined with a priori knowledge of the stakeholders involved in the experiment (LEI, supermarkets, government).

2. The representation of major food categories such as meat, dairy, fruit and vegetables, and groceries.

3. The availability of scanner data. In order to carry out the analysis and thus determine prices, we required data on both sales and volumes. This requirement was not met by products that are not pre-packed, for instance fruits and vegetables. There were only data on sales available for products

4 Konmar and Edah are no longer active in Dutch food retail. Laurus sold its Konmar and Edah outlets in 2006 to other supermarket chains and continued its activities under the Super de Boer formula. C1000 (Schuitema) is no longer part of the Ahold concern. 
that are not pre-packed. Therefore, mushrooms and potatoes were selected for the experiment, while apples were left out. This requirement also posed problems for products with variable weights, notably meat. Not all retailers have data with respect to both sales and volumes of meat. The analysis for meat was therefore restricted to the supermarket chains that had data on sales and volumes.

Eight products were selected on the basis of the above criteria: pork, minced beef, milk, eggs, potatoes, mushrooms, rice and muesli. The average number of organic SKUs for all eight products in an average test outlet during the experiment was 14-15 SKUs for Albert Heijn, Jumbo and PLUS (e.g. 2 per product); the figure was lower for all the other retail chains. The number of organic SKUs is limited taking into account the large number of SKUs for the selected products.

\subsection{Implementation}

The experiment was carried out in weeks 17-33, 2006 (17 weeks in total). The stakeholders agreed upon the following protocol.

Communication. In weeks 17 and 18, the price changes were communicated to consumers by regular promotion labels in the supermarkets. In the other weeks, the usual price labels were used. For meat, the price changes were indicated using regular promotion labels in all weeks of the experiment because of the large number of price promotions taking place in this category. The price changes were also communicated in week 17 by distributing folders in the ten communities. In the other weeks, no special attention was given to the price reductions. The experiment involved a price reduction, not a promotional activity.

The price reductions. The prices of organic food were reduced by various percentages. The prices of eggs, milk, muesli, potatoes and rice were reduced by $5,10,15,20$ and $25 \%$. The prices of mushrooms and meat were reduced by $8,16,24,32$ and $40 \%$ (see Table 2). The price reductions for eggs, milk, muesli, potatoes and rice were smaller than the price reductions for mushrooms and meat because the price gap between organic and nonorganic products is smaller for the former products. In each community, the same percentage price reductions were made in order not to disturb the competitive relations between retailers. However, the price reductions differed per product in each community; for instance, in Maassluis the price of organic pork was reduced by $24 \%$, while the price of organic potatoes was reduced by only $10 \%$. The government budgeted 1 million euros for the price subsidies. It in fact spent only 37,000 euros on them.

Availability. The retailers agreed to have organic varieties of all eight products on their shelves during the entire 17-week period. For pork, Albert 


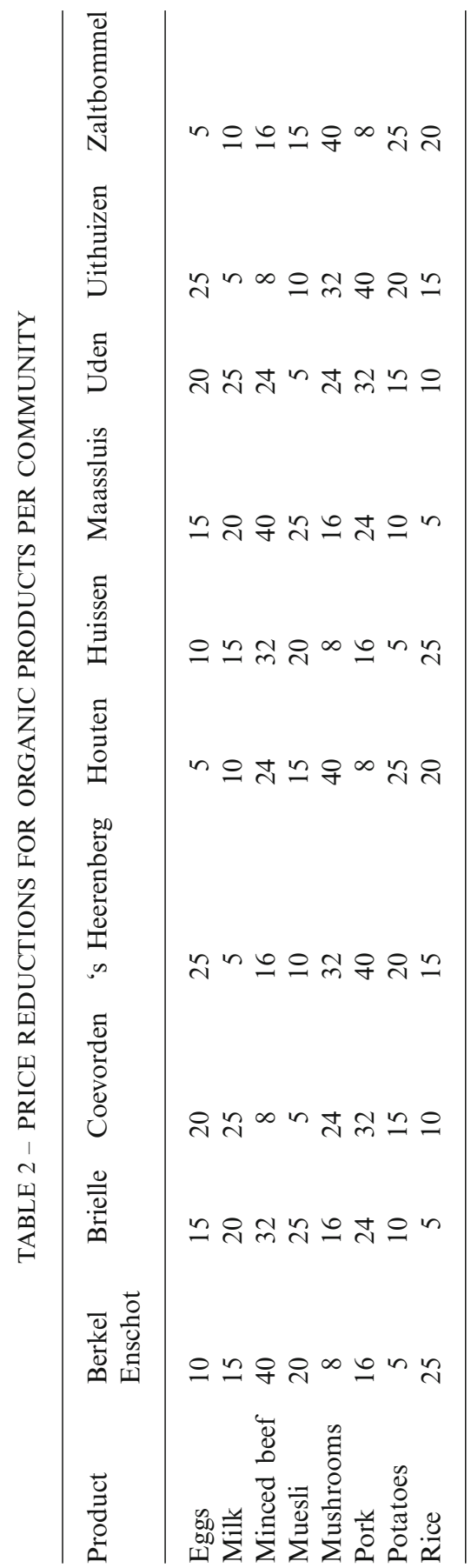


Heijn decided to reduce the price of organic schnitzels only. Organic muesli and organic mushrooms were not available in some retail chains.

Out of stock. In the agreement between the government and the CBL retail association, the retailers agreed to do their utmost to keep out-of-stock occurrences to normal levels.

Scanner data. We decided to use scanner data (IRI or AC Nielsen) rather than consumer budget data (GfK). The advantage of the IRI panel is that we were able to get data on all transactions in the ten communities. GfK's consumer budget panel would not have allowed us to do so. Moreover, consumer budget panel data apply to only a limited number of consumers. For organic food, budget panel data would have been particularly troublesome, because only a limited number of consumers buy organic products. The number of observations would have been too low to draw any conclusions.

The following problems arose at the beginning of the experiment and might have influenced the experiment and thus the results. (1) The availability of organic varieties. In the first weeks of the experiment, some organic varieties were withdrawn from the product assortment because they had hardly sold at all and had to be withdrawn from the outlets on a large scale due to the expiration of sell-by dates. This held in particular for meat. (2) The store checks indicate that out-of-stock levels for some products might have been relatively high at the beginning of the experiment. (3) Some retailers did not advertise the price reductions at all, while others advertised them vigorously. In some cases, the price reduction was not sufficiently visible in the store.

Store checks were undertaken in order to address these issues. If one of the problems was observed, the store manager was asked to solve it immediately. We have no insight into the importance of these problems, but based on the store checks, we believe that most of the above-mentioned problems were incidents rather than structural shortcomings.

\section{RESULTS}

\subsection{Data}

Scanner data were collected and provided by Information Resources Incorporated (IRI). The data comprise supermarket sales in 84 outlets over a total period of 86 weeks, that is, the period before the experiment (week 9, 2005, to week 16, 2006), the period in which the experiment was carried out (weeks 17-33, 2006) and the period after the experiment (weeks 34-42, 2006). The data are from the 42 outlets in which the experiment was carried out and from 42 control outlets. For each outlet that participated in the experiment, a comparable outlet that did not participate was selected from the IRI database. 
The scanner data provide information about both sales and volumes. Volumes are reported in kilograms, litres (milk) and units (eggs). Prices are determined as the quotient of sales and volume. The dataset makes a distinction between fixed and variable weight products: beef and pork are variable weight products, while all other products are fixed weight products. For beef and pork, volume data are available only for Albert Heijn, Jumbo and PLUS.

The data are on the lowest aggregation level possible: the ean code. The data refer to specific varieties of individual suppliers. At the highest aggregation level, each ean code refers to one of the eight product categories used in the analysis (eggs, milk, minced beef, muesli, mushrooms, pork, potatoes and rice). IRI makes a distinction between organic (EKO label) and non-organic products. Whenever possible, a further subdivision into major product categories was made in order to take account of differences in product varieties. Mushrooms, for instance, were subdivided into (organic and non-organic) 'white' and 'other' mushrooms.

\subsection{Descriptive Analysis}

Table 3 gives the budget shares of organic varieties for the test and the control outlets in weeks $1-16,2006$. The table shows that the average budget share of organic food in the test and in the control outlets is more or less the same for all products except muesli. Sales of organic varieties are relatively low for pork, rice and minced beef, and to a lesser extent for eggs and milk. Sales of organic varieties are very high for muesli. The sales shares differ per outlet. In some outlets the sales shares of organic varieties are substantially above the national average. This is indicated by the columns showing the maximum

TABLE 3 - MARKET SHARE OF ORGANIC PRODUCTS IN EUROS (WEEK 1-16 2006)

\begin{tabular}{|c|c|c|c|c|c|c|}
\hline \multirow[b]{2}{*}{$\begin{array}{l}\text { Product } \\
\text { group }\end{array}$} & \multicolumn{3}{|c|}{ Test outlets } & \multicolumn{3}{|c|}{ Control outlets } \\
\hline & Mean (\%) & $\begin{array}{l}\text { Standard } \\
\text { deviation }(\%)\end{array}$ & Maximum (\%) & Mean (\%) & $\begin{array}{l}\text { Standard } \\
\text { deviation }(\%)\end{array}$ & Maximum (\%) \\
\hline Potatoes & 9.7 & 5.6 & 26.6 & 8.9 & 4.0 & 16.0 \\
\hline Mushrooms & 8.2 & 4.1 & 17.5 & 7.4 & 5.5 & 21.8 \\
\hline Eggs & 5.1 & 6.2 & 34.5 & 4.4 & 3.1 & 12.0 \\
\hline Milk & 4.8 & 6.3 & 35.2 & 4.1 & 4.0 & 17.5 \\
\hline Muesli & 30.3 & 15.1 & 62.9 & 25.7 & 11.3 & 55.4 \\
\hline Rice & 2.3 & 1.9 & 10.4 & 2.2 & 1.1 & 5.6 \\
\hline Minced beef & 5.0 & 2.7 & 9.5 & 5.8 & 3.2 & 12.0 \\
\hline Pork & 2.1 & 1.8 & 5.3 & 2.1 & 2.0 & 7.2 \\
\hline
\end{tabular}

Source: IRI, all outlets. The data for minced beef and pork apply to Albert Heijn, Jumbo and Plus only. 
TABLE 4 - DESCRIPTIVE STATISTICS OF SALES, VOLUMES AND PRICES (ALL OUTLETS; MEAT ALBERT HEIJN, JUMBO AND PLUS ONLY)

\begin{tabular}{|c|c|c|c|c|c|c|c|c|c|c|c|c|}
\hline & \multicolumn{4}{|c|}{ Sales (in euros) } & \multicolumn{4}{|c|}{ Volume } & \multicolumn{4}{|l|}{ Price } \\
\hline & \multirow{2}{*}{\multicolumn{2}{|c|}{$\frac{\text { Organic }}{\text { Mean SD }}$}} & \multicolumn{2}{|c|}{ Non-organic } & \multicolumn{2}{|c|}{ Organic } & \multicolumn{2}{|c|}{ Non-organic } & \multicolumn{2}{|c|}{ Organic } & \multicolumn{2}{|c|}{ Non-organic } \\
\hline & & & Mean & $\mathrm{SD}$ & Mean & $\mathrm{SD}$ & Mean & $\mathrm{SD}$ & Mean & $\mathrm{SD}$ & Mean & SD \\
\hline Eggs & & 290 & & 9,474 & 8,608 & 1,282 & & & 0.27 & 0.01 & 0.15 & \\
\hline Milk & 6,080 & 551 & & 7,956 & 7,104 & 563 & 251,639 & 14,213 & 0.86 & 0.02 & 0.60 & 0.00 \\
\hline Minced beef & 1,918 & 411 & 42,953 & 8,703 & 209 & 55 & 8,870 & 2,805 & 9.31 & 0.85 & 4.98 & 0.53 \\
\hline Muesli & 503 & 54 & 1,671 & 171 & 156 & 18 & 851 & 112 & 3.23 & 0.13 & 1.97 & 0.11 \\
\hline Mushrooms & 1,901 & 494 & 22,887 & 4,564 & 323 & 77 & 5,778 & 1,173 & 5.89 & 0.32 & 3.97 & 0.13 \\
\hline Pork & 1,374 & 185 & 84,340 & 13,897 & 125 & 20 & 11,164 & 1,548 & 11.01 & 0.48 & 7.55 & 0.45 \\
\hline Potatoes & 5,975 & 2,388 & 69,165 & 14,200 & 5,723 & 2,663 & 108,157 & 20,264 & 1.08 & 0.15 & 0.66 & 0.19 \\
\hline Rice & 429 & 55 & 22,123 & 2,625 & 211 & 26 & 11,620 & 1,670 & 2.04 & 0.09 & 1.91 & 0.09 \\
\hline
\end{tabular}

observations in the dataset. Table 4 presents the means and standard deviations of product volumes, sales and prices.

Figure 1 shows the development of the average price of organic and nonorganic products at the aggregate level. By comparing prices in test and control outlets, we gained some insight into the price gap between organic and non-organic products, as well as into the price reductions realized in the experiment. The prices calculated are unweighted averages of weekly data; they are not based on a price index. This implies that weekly changes in consumer buying behaviour might influence the prices derived from the data. We also want to stress that prices refer to all brands and package sizes. Organic products are typically unavailable in bulk discount packages. The price differences between non-organic A labels and organic varieties are smaller than Figure 1 suggests.

Figure 1 clearly shows that the experiment led to a substantial price decrease for organic products in the selected outlets, and that this decrease reduced substantially the price gap between organic and non-organic varieties. For rice, the average price of organic products even fell below the average price of non-organic rice. Note, however, that non-organic rice also refers to more expensive product varieties, such as basmati rice.

Figure 1 also shows that, apart from the structural break caused by the experiment, most prices fluctuate around a given average. In technical terms, the price data are mean stationary. Pork prices fluctuate around an upward trend in this period, while rice prices fluctuate around a downward trend. The price data for both products are trend stationary. Potato prices fluctuate more wildly. Potato prices might be non-stationary. 

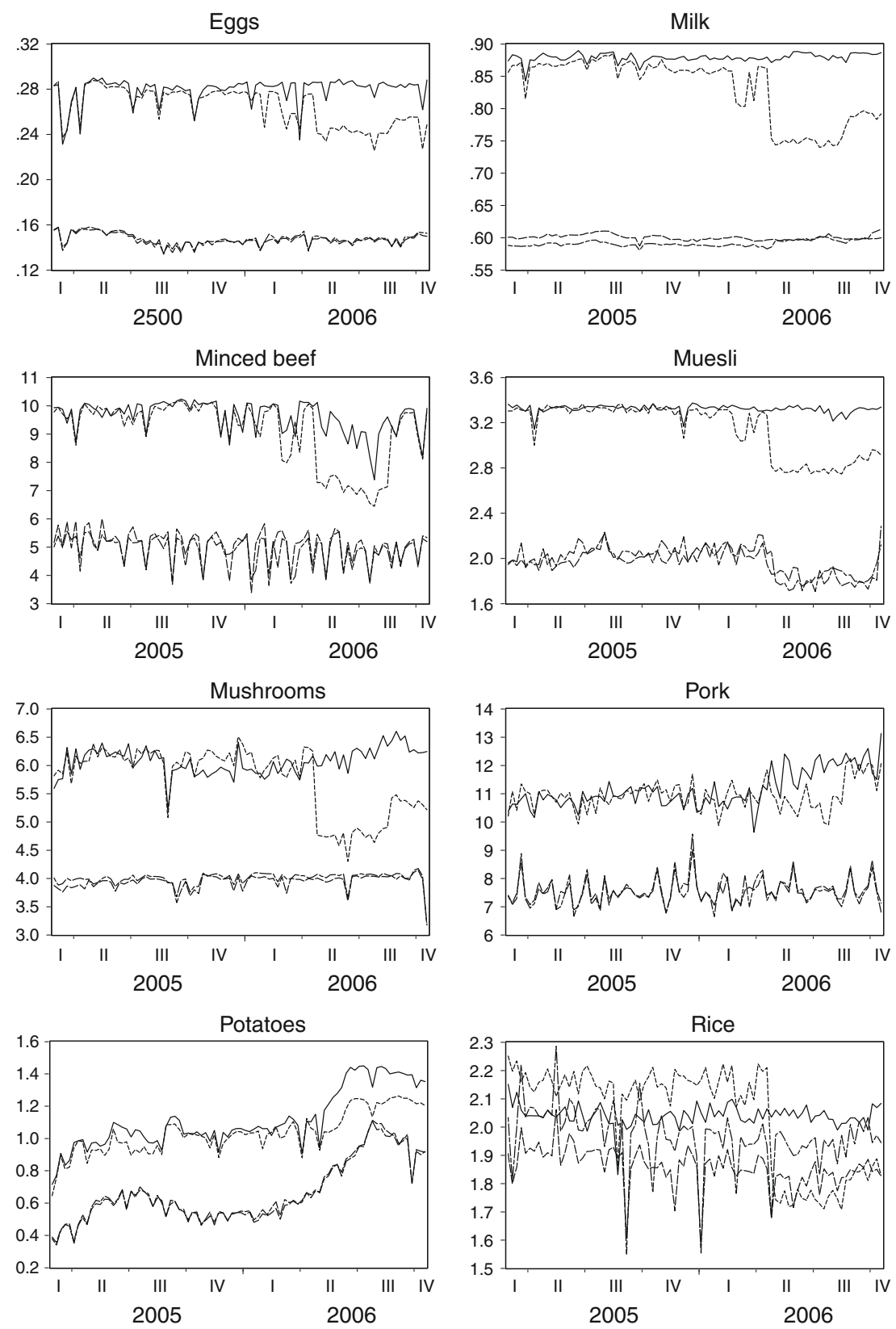

- Organic, control group ----- Organic, test group - - Non-organic, control group - - Non-organic, test group

Figure 1 - Price development of organic and non-organic products (€ kilo, week 9, 2005 - week 42, 2006) 
Figure 2 presents developments in the volume sold for the control and the test outlets. The impact of the experiment on the volume sold is not clear from mere observation. For pork and minced beef, for instance, although volumes develop more favourably in the test outlets in the experiment period, the overall picture is not clear. In general, volume sold does not develop around a mean average or a trend. There are cyclical patterns and seasonal peaks (potatoes) and troughs (milk). This might indicate non-stationarity, as well as the need to incorporate seasonal patterns in the demand system.

Sales of organic eggs, milk and muesli developed less favourably in the test outlets than in the control outlets during the experiment (Figure 3). This is probably due to the difference in price developments in both groups of outlets and might point to a low own-price elasticity of demand. For the other products, the impact of the experiment is less clear. Again, for some products, sales develop around a mean average or a mean price (rice), while sales of other products (eggs, milk, potatoes) fluctuate more wildly. For these products, sales might be non-stationary.

\subsection{Econometric Analysis}

For each product separately, we consider the sales and prices of the organic variety and of the non-organic variety in order to compare the test group of outlets with the control group in such a way that own- and cross-price elasticities are estimated and tested for being of equal size between test and control group. To perform this analysis, we start with the following loglinear model:

$$
\begin{aligned}
\Delta s_{v t, t}-\Delta s_{v c, t}= & \alpha_{v}+\alpha_{v n t} \Delta p_{n t, t}-\alpha_{v n c} \Delta p_{n c, t} \\
& +\alpha_{v o t} \Delta p_{o t, t}-\alpha_{v o c} \Delta p_{o c, t}+u_{v, t}
\end{aligned}
$$

where $v$ can be either $n$ (non-organic) or $o$ (organic), $s$ is the natural logarithm of the sales in units, $p$ is the natural logarithm of the retail price per unit, $t(c)$ indicates the test (control) group, subscript, ' $t$ ' stands for the time index $(t=1, \ldots, T)$ with $T$ the number of time series observations in the sample, $\Delta x_{t} \equiv x_{t}-x_{t-1}$ for any time series $x_{t}, u_{v, t}$ is the residual term and the $\alpha$ 's are the coefficients to be estimated. The rationale for considering the difference $\Delta s_{v t, t}-\Delta s_{v c, t}$ is that the effect of common events like holidays is cancelled out before appearing as vertical outliers in the estimated residuals (the vertical outliers that might still show up are eliminated by impulse dummies). Moreover, because there is no price competition between the test and control group retail outlets, the price coefficients represent elasticities. Any dynamics left are captured by an ARMA model in the residual term as selected by the Box and Jenkins (1970) procedure, assuming that the COMFAC restrictions (Hendry and Mizon 1978) are not seriously violated. If a unit root is found in the MA term, then we drop the $\Delta$ 's from the model so that a log-linear 

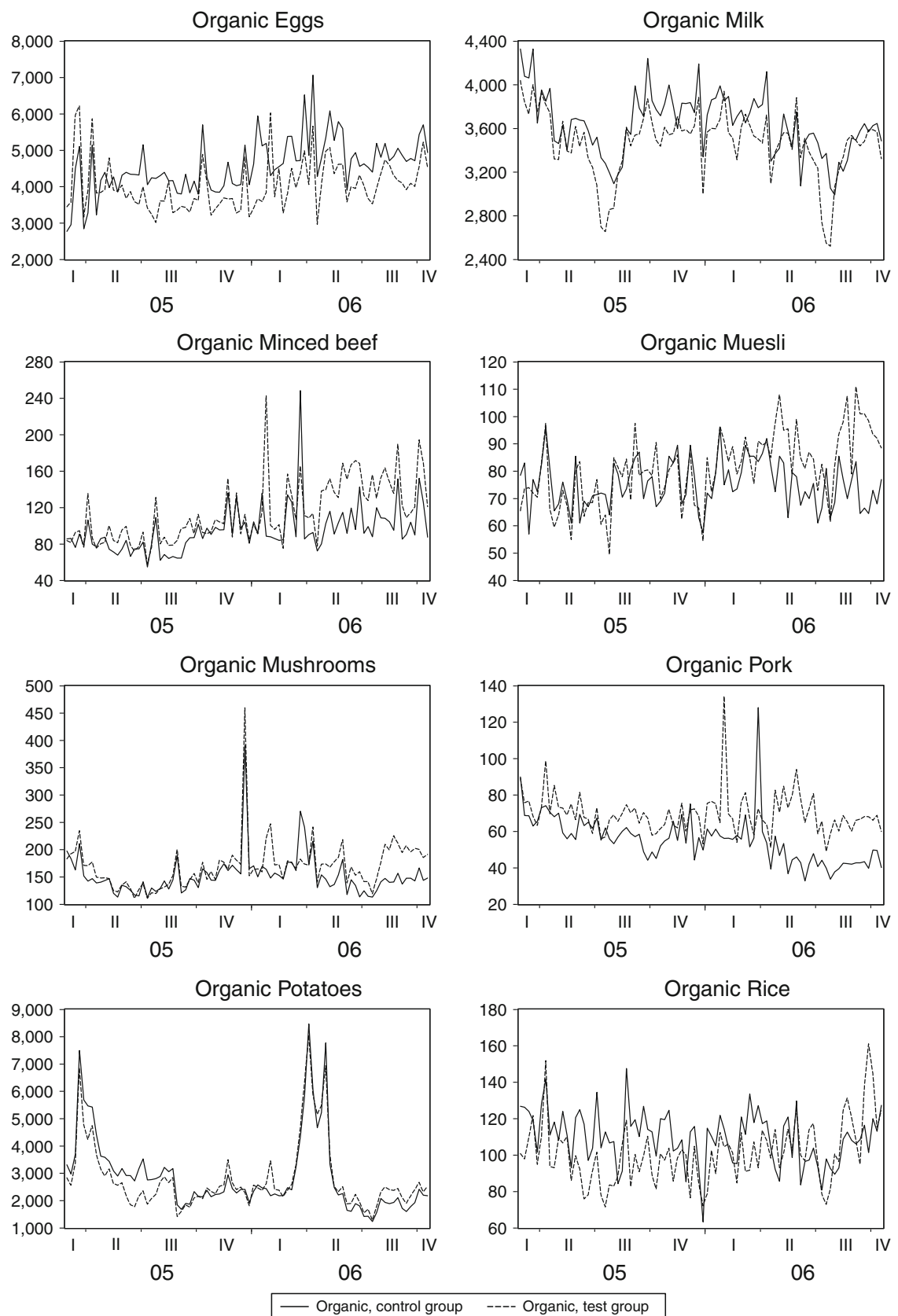

Figure 2 - Volume development of organic products: control and test group (kilos, week 9, 2005 - week 42, 2006) 

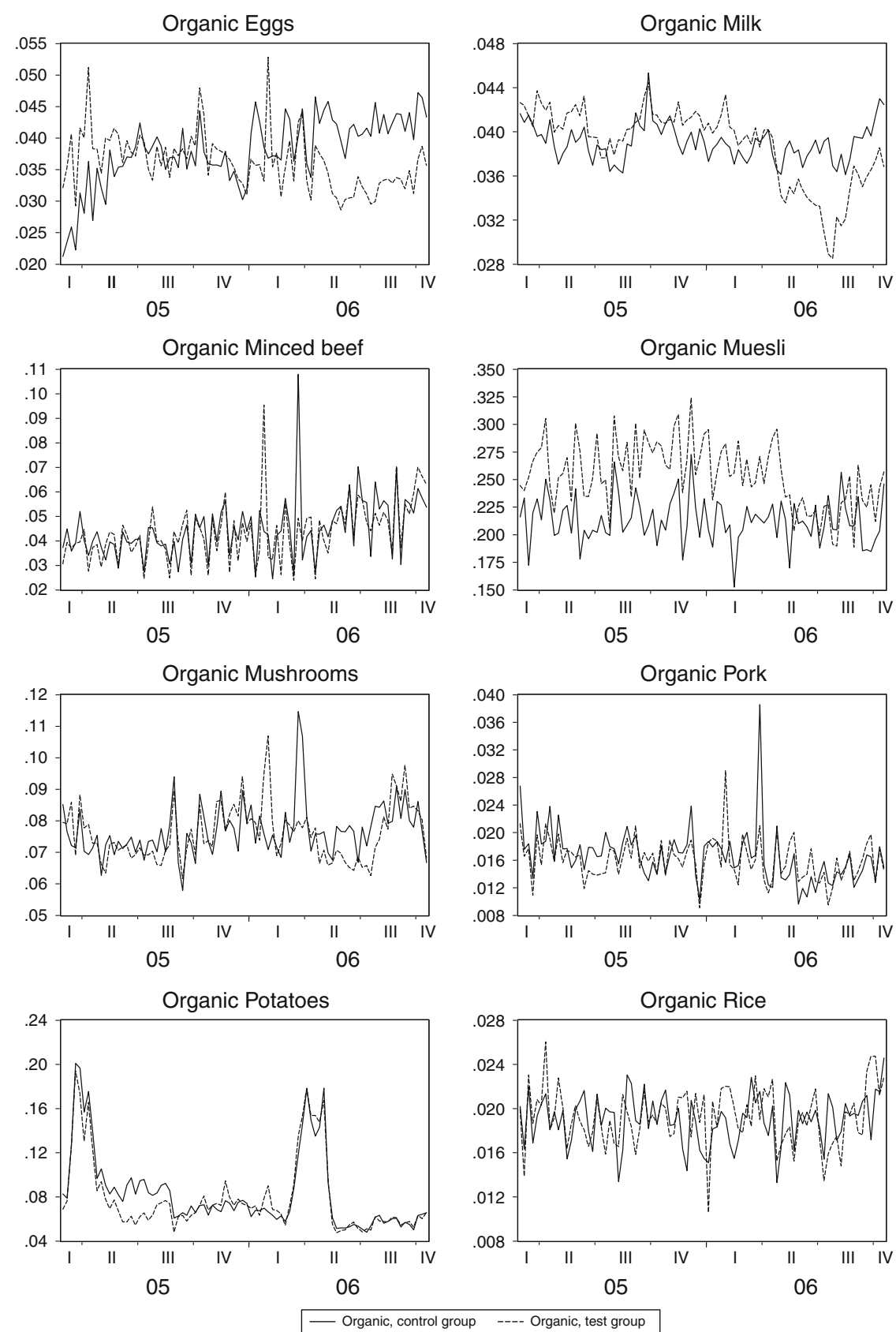

Figure 3 - Budget share of organic products: control and test group (\%, week 9, 2005 - week 42, 2006) 
TABLE 5 - ESTIMATES OF OWN- AND CROSS-PRICE ELASTICITIES WITH RESPECT TO THE DEMAND FOR NON-ORGANIC AND ORGANIC VARIETIES OF FRESH FOOD IN DUTCH SUPERMARKETS

\begin{tabular}{|c|c|c|c|c|c|c|}
\hline \multirow[t]{3}{*}{ Product } & \multicolumn{6}{|c|}{ Price elasticities with respect to } \\
\hline & \multicolumn{2}{|c|}{ Non-organic demand } & \multirow[t]{2}{*}{ Effect } & \multicolumn{2}{|c|}{ Organic demand } & \multirow[t]{2}{*}{ Effect } \\
\hline & Own-price & Cross-price & & Own-price & Cross-price & \\
\hline Eggs & $-0.80(0.21)$ & NS & Permanent & $-1.43(0.31)$ & NS & Permanent \\
\hline Milk & NS & $0.14(0.06)$ & Permanent & NS & NS & Transitory \\
\hline Minced beef & $-1.55(0.12)^{*}$ & $0.28(0.10)$ & Transitory & $-0.63(0.19)^{* *}$ & $0.44(0.22)$ & Permanent \\
\hline Muesli & NS & NS & Transitory & NS & NS & Transitory \\
\hline Mushrooms & $-1.39(0.29)$ & NS & Transitory & $-0.46(0.08)^{* *}$ & NS & Transitory \\
\hline Pork & $-0.70(0.16)^{* *}$ & NS & Transitory & $-1.13(0.27)$ & NS & Permanent \\
\hline Potatoes & $-1.46(0.15)^{*}$ & NS & Permanent & $-1.42(0.27)$ & NS & Permanent \\
\hline Rice & $-1.95(0.18)^{*}$ & NS & Transitory & NS & NS & Transitory \\
\hline
\end{tabular}

Standard errors in parentheses.

$N S$ non-significant.

* Significantly smaller than minus one; ** indicates significantly larger than minus one.

specification in levels remains (cf. Campbell and Mankiw 1987). Given the assumption that in such a simple price-quantity relationship like (1) stochastic trends must be missing, cointegration is ruled out and hence, a specification in levels indicates that the shock in sales as represented by the price elasticity will be transitory instead of permanent (e.g. Dekimpe and Hanssens 1995). Finally, having selected a final specification, the equality of the price elasticities is assessed by testing for the coefficient restrictions

$$
\alpha_{v n t}-\alpha_{v n c}=0 \text { and } \quad \alpha_{v o t}-\alpha_{v o c}=0
$$

If the price reduction for the organic variety really triggers a significant demand shift from non-organic to organic, we may expect much higher (in terms of absolute value) price elasticities with respect to the demand for organics in the test stores (specifically, $\alpha_{n o t}$ and $\alpha_{o o t}$ ) as compared to the control group. The empirical analysis did not reveal any evidence of such a difference between the test and control group elasticities. Consequently, in Table 5 we present the price elasticity estimates as obtained under the coefficient restrictions in (2).

For the sake of econometric efficiency, the non-significant estimates are omitted from the final equations selected from (1) and hence also from Table 5. None of the own-price elasticities with respect to the consumer demand for organic produce that do show up in Table 5 is significantly smaller than minus one, implying that price reductions for the organic products do not 
increase their sales value, although in the case of eggs, pork and potatoes the point estimates suggest demand to be more often price elastic than inelastic. Consumer demand for organic mushrooms and minced beef is even significantly price inelastic. In contrast, the demand for the non-organic products appears to be significantly price elastic with respect to minced beef, potatoes and rice. The cross-price elasticities found for minced beef indicate demand switching behaviour between the organic and non-organic varieties. But to summarize, as we do not find any own-price elasticities with respect to the demand for organic products that are smaller than minus one and that have a permanent effect, lowering consumer prices does not seem to be the trigger for the desired growth in organic consumption.

The price elasticities of demand found are low compared to those found elsewhere in the literature on organics. Wier and Smed (2000) found price elasticities of between -2.3 and -1.6 for Danish demand for cereals, dairy, meat and other food. Hansen $(2003,2004)$ found lower price elasticities for the same product categories: from -0.8 to -0.5 . For the USA, Dhar and Foltz (2003) found a price elasticity of -1.4 for milk. Glaser and Thompson (1998) found price elasticities of around -2 for frozen vegetables, but relatively high price elasticities for specific types of milk: from -3.6 to -9.7 (Glaser and Thompson 2000).

\section{EVALUATION}

The price elasticity of demand is low for organics. There is no sign that there is a turning point in consumer demand beyond which consumers switch en masse from regular to organic food. This is either due to a lack of knowledge with respect to the price reductions during the experiment or due to consumer preferences. We will explore both arguments using the results of a questionnaire that was conducted parallel to the price experiment in the communities that took part in the experiment.

Both before and during the experiment, IRI conducted interviews with consumers as they left the supermarkets that participated in the experiment. The interviewers interviewed people who had bought at least one of the products involved in the experiment. The interviewers identified buyers of organic versus regular varieties. The sample of respondents was deliberately chosen to be non-random in order to ensure that there were sufficient buyers of organic varieties in the sample.

The interviews were held in the week before the experiment (week 16), at the beginning of the experiment (week 23) and at the end of the experiment (week 33). ${ }^{5}$ In total, 4,728 people were interviewed: 1,293 in measurement

5 The last interviews were held in week 28 in the north of the Netherlands because of the summer holidays. 
$1,1,774$ in measurement 2 and 1,661 in measurement 3 . Of the persons interviewed, $28 \%$ only buy regular products. Of the respondents who buy organic products, $41 \%$ do so weekly and $59 \%$ occasionally. A substantial proportion of the respondents who indicated that they buy organics, had not bought organics during this particular visit to the supermarket.

\subsection{Awareness of Price Reductions}

The problem statement presumes that consumers react to changes in consumer prices by adapting their buying behaviour. However, consumers change their buying behaviour only if three conditions are met (Van Heerde et al. 2005):

1. they are aware of the price change

2. they are able to react to the price change

3. they are willing to change their buying behaviour.

With respect to these three conditions, we may formulate the following a priori expectations:

1. One may expect that consumers are aware of the price changes. The price reductions were communicated through folders and price labels and were implemented for a four month period. ${ }^{6}$

2. Consumers are able to switch from one product variety to another, because we are dealing with products that are bought daily (or at least weekly). For durable products, consumers might face large switching costs, such as contractual obligations (e.g. a telephone contract) or recent purchases (e.g. a couch).

3. If the above expectations hold, changes in consumer buying behaviour depend to a large extent on consumer motivation. If consumers perceive that organic products have value added over non-organic products, then some consumers may be expected to switch to organic products or to buy more organic products when organic food prices are reduced. If consumers perceive the price change but do not switch from non-organic to organic food, there might be a bottleneck with respect to the value added organic products are supposed to have. The number of organic varieties might be too low or might not meet the preferences of the Dutch consumer.

The first condition is crucial for the results of the analysis. Consumers were not constantly informed about the price reductions during the experiment.

6 A counter argument is the fact that the budget share of most products in total consumer expenses is low. The consumer might very well be unwilling to compare prices in a product group such as muesli. However, research shows that even for a product group such as ketchup some consumers make use of price information (Van Heerde et al. 2005). 
Consumers had search costs during the experiment, as they do in regular settings. The information provided was limited. During the first two weeks of the experiment, the price changes were communicated via promotion labels and folders; during the other weeks, this information was confined to regular price labels. Consumers had to take the time to read and process the price information.

Consumers' price awareness during the experiment was investigated by means of the questionnaire. Consumers were asked to name the price of the product they had just bought. One fifth of the respondents said that they did not know its price. The consumers of organics knew the prices of the items they had just bought, both before and during the experiment. Prices of organic items are overestimated a little. Some of the consumers also indicated that they were aware of the price reductions.

Consumers who had not bought any organics during the visit to the supermarket were also asked to indicate the price of the non-organic products and to estimate the price of the organic products. We used this data to calculate the mark-up of organics over non-organic products. Before the experiment, the mark-up was estimated to be $50 \%$, which is close to the actual price difference of $58 \%$ (Table 6). People who do not buy organics have a reasonable perception of price differences. During the experiment, the mark-up was estimated to be $56 \%$ during the first measurement (week 23) and $48 \%$ during the second measurement (week 33). Perceptions of price differences did not really change for consumers who had not bought any organics during this particular supermarket visit. Of course, the people who did not buy organics before the experiment and did buy organics during the experiment had switched from being non-buyers to buyers of organics. We conclude that many people who do not buy organics did not perceive the price reductions. This is partly due to the habit formation: consumers do not collect and process product information every time they visit a supermarket (Steenkamp 1997).

Thus, consumers of organics perceived price differences. It is likely that a part of the non-buyers of organics also perceived the price reductions. We do not know how large this group is. However, many - probably most - consumers did not perceive the price reductions. If one takes into account that perceived price differences are substantially higher than the willingness to pay, it is not surprising that the impact of the price reductions on consumer demand was limited. Consumers possibly need more time to observe changes in prices.

\subsection{Value Added}

The questionnaire was also used to find out how consumers perceive organic versus non-organic food and what their motives were for selecting the items they had just purchased. Consumers perceive organic products as being good for the environment and animal welfare (Figure 4). Organic and non-organic 


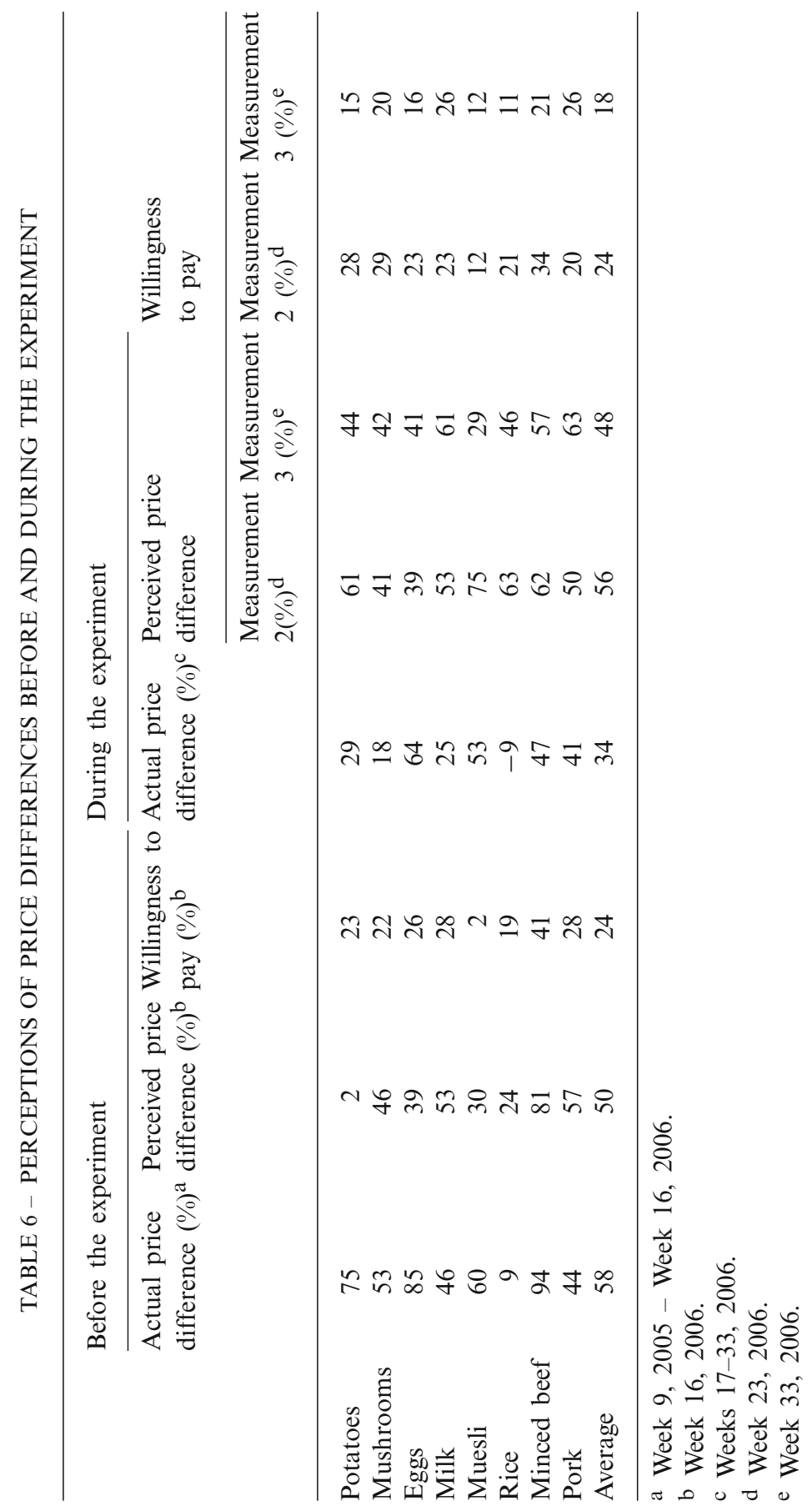




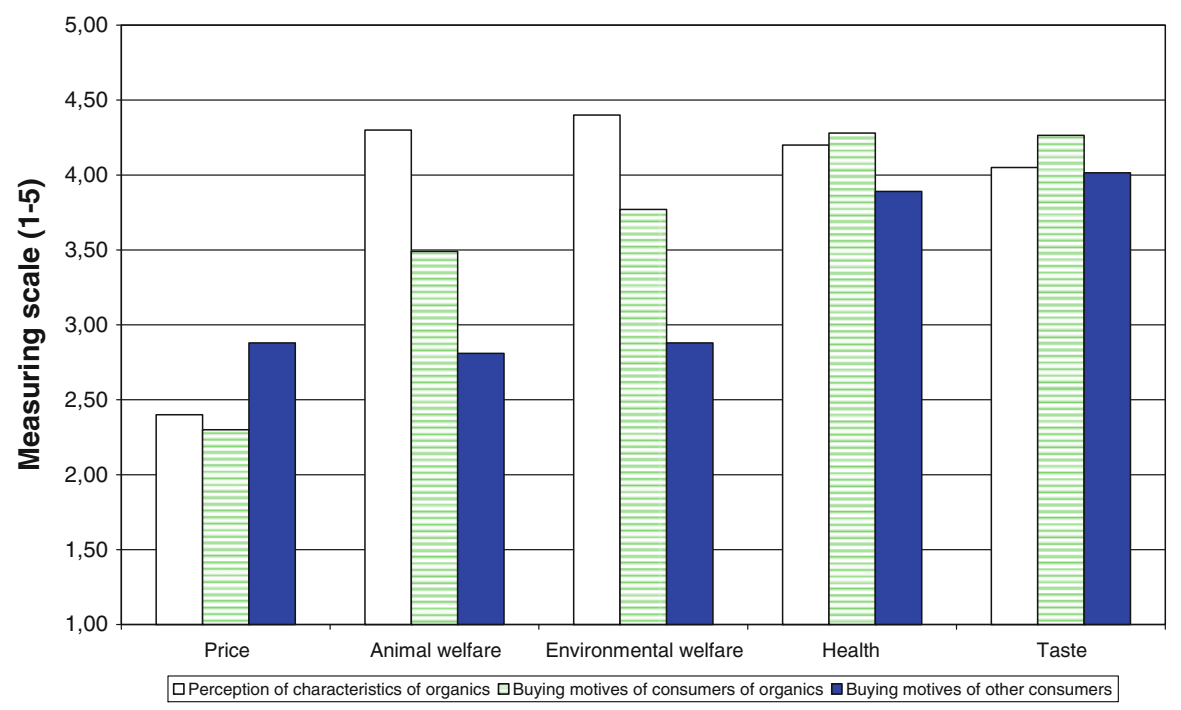

Figure 4 - Consumer perceptions of and motives for buying organic food versus non-organic food

food products do not really differ with respect to such perceived attributes as taste, health and quality. This holds for both consumers who regularly buy organics and other consumers. People buy particular food items because they are tasty, healthy and of good quality, and out of habit formation. Figure 4 illustrates that while consumers perceive organic food as being animal and environment friendly, neither characteristic is an important buying motive. This applies particularly to consumers who do not buy organics. Animal welfare, environment friendliness and health are more important buying motives for consumers of organics than for other consumers. Buyers of organics care more about the social characteristics of food items and about their (presumed) healthiness than buyers of non-organic food. Note that organic food is also considered to be expensive, particularly by consumers who do not buy organics.

\section{CONCLUSION}

In order to find out whether price differences between organic and conventional food explain the low market share of organics in total food consumption, the Dutch government organized a real-life experiment in which the prices of organic products were reduced by up to $25 \%$ for eggs, milk, muesli, potatoes and rice and by up to $40 \%$ for minced beef, mushrooms and pork. The aim of the study was to establish how sensitive consumer demand is to 
changes in prices and, more specifically, whether consumers would switch to organic food if the price difference between organic and conventional food disappeared. The government wished to establish the price elasticity of demand outside the realm of observations that are available in market data.

The price elasticity of the demand for organics is low. The price elasticity for organic milk, muesli and rice does not differ significantly from zero. The price elasticity for the other organic products ranges from -0.46 to -1.43 . None of the price elasticities with a value below -1 differs significantly from -1 : demand for organics is never found to be price elastic. This implies that a reduction in the price gap gives a small boost to consumer demand. It will not have a large impact on the budget share of organics - the government's policy objective - because the increase in consumer demand is undone by the price decrease.

The price elasticity of demand is low for three reasons. First, not all the consumers observed the price reductions. There was no change during the experiment in the price differences between organic and non-organic products perceived by many consumers who buy non-organic products, even though the price reduction was communicated through promotional labels and folders in the first two weeks of the experiment. Second, the offer of organic varieties is limited. Consumers might not be stimulated to switch from conventional to organic food if the variety of conventional food items on offer is much wider than the variety of organic food items. Third, consumers perceive organics as superior in terms of environment and animal friendliness. However, social attributes are a buying motive for only a limited number of consumers.

The results of the experiment are useful in assessing current discussions on the role of prices in promoting socially desirable buying and consumption behaviour. There is discussion about the possible taxation of animal (meat) products in order to reduce the environmental load of livestock production, and the taxation of nutrient-rich food in order to reduce obesity. The empirical results show that consumers do react to price changes, but only to a limited extent. Taxing food will work, but probably only in conjunction with other measures that influence consumer information and the availability of good alternatives.

Open Access This article is distributed under the terms of the Creative Commons Attribution Noncommercial License which permits any noncommercial use, distribution, and reproduction in any medium, provided the original author(s) and source are credited. 


\section{REFERENCES}

Biologica (2010), EKO Monitor Jaarrapport 2009, www.biologica.nl.

Box, G. and G. Jenkins (1970), Time series analysis: Forecasting and control, Holden-Day, San Francisco.

Bunte, F.H.J. (2004), In de markt geprijsd, LEI, Den Haag.

Campbell, J.Y. and G. Mankiw (1987), 'Are Output Fluctuations Transitory?', The Quarterly Journal of Economics, 102, pp. 857-880.

Dekimpe, M.G. and D. Hanssens (1995), 'The Persistence on Marketing Effects on Sales', Marketing Science, 14, pp. 1-21.

Dhar, T. and J.D. Foltz (2003), 'Market Structure and Consumer Valuation in the rBST-Free and Organic Milk Markets', Paper Presented at the AAEA Annual Meeting, Montreal, July 27-30, 2003.

Glaser, L.K. and G.D. Thompson (1998), 'Demand for Organic and Conventional Frozen Vegetables', Paper Presented at the AAEA Annual Meeting, Nashville, August 8-11, 1998.

Glaser, L.K. and G.D. Thompson (2000), Demand for organic and conventional beverage milk, paper presented at the Western Agricultural Economics Association, Vancouver, June 29-July 1, 2000.

Hansen, L.G. (2003), Organic crowding out: A study of Danish organic food demand, AFK, Copenhagen.

Hansen, L.G. (2004), Organic food demand: evidence from a Danish micro panel, AFK, Copenhagen.

Hendry, D.F. and G.E. Mizon (1978), 'Serial Correlation as a Convenient Simplification, Not a Nuisance: A Comment on a Study of the Demand for Money by the Bank of England', Economic Journal, 88, pp. 549-563.

LEI (2009), Landbouw-Economisch Bericht LEI, Den Haag, rapport 2009-047.

MLNV (2000), Een biologische markt te winnen: Beleidsnota biologische landbouw 2001-2004.

MLNV (2004), Beleidsnota biologische landbouw 2005-2007.

Steenkamp, J.-B.E.M. (1997), 'Dynamics in Consumer Behavior with Respect to Agricultural and Food Products'. in: B. Wierenga, A. van Tilburg, K. Grunert, J.-B.E.M. Steenkamp and M. Wedel, (eds.), Agricultural Marketing and Consumer Behavior in a Changing World, Kluwer Academic Publishers, Boston, pp. 140-185.

Van der Eerden, Ludger, Joost Hoogendoorn en Maurits Butter, 10\% Biologische landbouw: mag het ook ietsje meer zijn?, Delft: TNO-STB 03-08b, 2003.

van Heerde, H.J., M.G. de Kimpe and W.P. Putsis (2005), 'Marketing Models and the Lucas Critique', Journal of Marketing Research, 42, pp. 15-21.

Wier, Mette and Sinne Smed (2000), Forbrug af okologiske fodevarer; Del 2: Modellering af eftersporgslen, Copenhagen, DMU: rapport 319. 